\title{
Climatic Conditions Dependent Residential Building Materials and Facade Design: A Case Study of Tehran, Iran
}

\author{
Mohammad Fahima \\ Azad University, Iran \\ Study Area: Tehran, Iran \\ Coordinates: $35^{\circ} 41^{\prime} 46^{\prime \prime N} 51^{\circ} 25^{\prime} 23^{\prime \prime E}$
}

Department of Architect Engineering, Khomein Branch, Islamic

Key words: Heblex, Nano-glass, Oleg method, Nano skins, Solar-cells

\section{Abstract}

The climatic conditions of a region are one of the issues that must be kept in mind while designing any facade related to civil construction. Front view of the building is such a part of the design for any building which is indeed the very first part of the building which remain in direct contact with the outside world. The exterior design of the building is the most important part of the climatic design. The Tehran initiates with the foothills area so by using design in harmony with the region's climate more savings can be achieved. In this regard, first, you must correctly identify the area followed by suitable proposals in order to design inconsistent with the climate of the area. Present paper is based on the descriptive type and analysis of library stuffs.

aspect after expansion of construction. In this respect, the main question here arises is about the foundations of residential building design in harmony with the Tehran climate. To answer this question we must have the proper knowledge about the climatic conditions of the first region of Tehran. Further, about the proper characteristics of the building materials having consistent with the climate.

In our study, we considered the design of facades as a dependent variable and materials appropriate with the climateas the independent variable.

Till date numerous projects on this subject have been done but none of them paid any attention towards of Tehran and this is the innovation aspect of this research.

The targetted audience of this research was designers and builders of the residential area lying in the first region of Tehran. Another audience of this research was the legislators and municipal officials of the first region of Tehran. The residents of the building in 1st region also are among targetted audience.

\section{Some background literature:}

Various researches have been done in this regard as AnnaMaria (2009) evaluated specif ic vernacular dwelling types and their response to climate, based on the passive design principles which could be adapted to current architectural practices in the area, in order to optimise the relationship between site, building and climate. Further, Mahmudi \& Nabavi, (2011) found the impact of technology on sustainable development and introduces some new material which is consistent with the climate. Tabriz et al. used in the facade design. The facade design has differen

*Corresponding Author: mohammad.fahima2@gmail.com 
(2012) explained index sustainability factors and in addition compare the energy loss of the outer shell of traditional and modern buildings in Tabriz.

Climatology is a science that tries to explain differences in the nature of the weather in different places and its integration with the elements of the natural environment with respect to the human activities. Climatology is the scientific study of climate which means describes and displays the difference between climate and the use of climate information in solving social problems. In other words, Climatology is discovering and explaining the natural behaviour of the atmosphere and exploit it for the benefit of humans. These engravings have a direct contact with culture and tradition ceremonies and excuses of people of a country and it is necessary to protect and transfer to the next generations (Naeeni \& Teimouri, 2016).

Applied climatology, searches weather and other related phenomena and its potential effects on human comfort and the possibility of change in climate so that human can cope as per his/her needs. Thus, a new combination of general climatologies such as biological, agricultural, medicine, architecture and urban climatology has been developed and spread.

Today the importance and necessity regarding the proper knowledge about the climatic conditions for design and construction of all residential buildings are important from two perspectives. On one hand, buildings designed in harmony with the climate in terms of human thermal comfort have better conditions and variety of daily and seasonal changes in light, heat and airflow create pleasant spaces in the buildings, and on the other hand harmony with the climate in these building causes to saves energy to control environmental conditions. In some climates, internal conditions of buildings in harmony with the climate can be adjusted naturally and without the mechanical heating systems needed for human comfort level. To achieve comfort conditions, implementing ways to provide comfort in buildings is the most important factor. To continue the war on the circumstances in building construction some points must be followed.

1. Eco Building

2. Select materials appropriate to the environment

Construction should be selected as per the areas and climates by keeping in mind the traditional architecture of the region. Climate scientists should provide proper guidelines for comfort in buildings and natural environments by better and more recognition of climate. Wider recognition should be provided in a relation between past Architecture and prevailing climatic conditions and organise the status quo regarding the past, present and future to a favourable condition. Design buildings in urban, rural and industrial condition should fully intend to climate and perfect design provided according to the topography of the Earth's tilt relative to the latitudes and conditions in geographic directions and the amount of solar energy in summer and winter. However, adoption of local materials in developed countries can be hindered by the loss of traditional building crafts and a lack of appropriate building standards. (Morel et al., 2001).

The climatic design: it means a plan that could be in coordination with its surrounding natural environment and enjoying more of natural forces on the ground as much as possible to ensure the proper natural environment for users.

The climatic design means a plan that could be in coordination with its surrounding natural environment and enjoying more of natural forces on the ground as much as possible to ensure a proper natural environment for users.

The term "Implementation of special climatic" is special construction methods aimed at lower the costs of heating and cooling by using natural energy flows in buildings. To achieve this aim, two actions should be taken:

1. Check local weather conditions for human comfort

2. The structural design of buildings (structural design means the size of the building, its area, type of walls, the size of windows etc.).

Methods for achieving more comfort level, some of the basic targets are as follows:

1. Reduce heat loss in the building

2. Reduced wind effect in heat dissipation 3. The use of solar energy and building heating

4. Protection of building from direct sunshine in the summertime.

5. Climate elements Impact on architecture are solar radiation, temperatures, humidity, wind, rainfall (ElRayes \& Moselhi, 2001; Fitzharris, 2001)

Climate elements Impact on architecture: human comfort is the result of climatic elements interaction such as solar radiation, temperature, humidity, wind and precipitation. In relation to the effects of weather on the design and shape of the building and its establishment below points shall be emphasized:

i. Suitable location.

ii. Buildings arrangement relative to each other and in relation to the influence of climatic elements.

iii.The resistance of materials used against the elements and weather factors.

iv. Plan, shape, and design of the building with respect to the weather conditions

v. Factors supporting comfort level based on architecture compatible with the climate.

Resistance of materials used in the building: in general, high temperatures and sudden changes in temperature do lead to many problems (Xia et al., 2016). 
While being insulated against heat exchange, sometimes competes with girder in terms of strength. Or in the humid forest like north, materials used in buildings shall be resistant to moisture and corrosion caused by (the chemical and physical weathering). The temperature is of very important climatic elements that should be considered in building especially in the case of metal materials that temperature changes cause to expansion and contraction of them. In this case, using of colours that reflect the sun's range of insulation can help to reduce these problems. In general, high temperatures and sudden changes in temperature will lead to many problems.

When the temperature falls below freezing point quickly, concrete, stone, and other materials of the building are subject to damage. Ice expansion at the joints and cracks generally lead to breakage and destruction of buildings, so especially in the desert cities that heat range is much; the walls, roofs, and building materials should be selected according to their coefficient of expansion (Powers, 1975). The temperature in the low-latitude adversely affects the paved and tarred roof. Because when the roofs are exposed to the sunshine, the temperature sometimes reaches 130 to $140^{\circ} \mathrm{F}$. this issue cause to melting of bitumen at the building's roof surface and increase the temperature of Indoor space. Other effects of temperature are the performance of building construction workers on the project. Relative humidity in the air is also important due to its effect on materials building, covering or coating materials and colours. Metals under conditions of high relative humidity are highly susceptible to deterioration and gradual corrosion. Physical and chemical corruption of colours also increases with high humidity. Rain not only increases the damaging effects of moisture but has direct physical effects on open surfaces as well. Heavy rains damaged and worn out buildings of clay and dirt and create runoff and floods that destroy the foundation. This type of rain penetrates freshly poured concrete and worn earth embankments and stopped or slow down most of the activities. Dams, channels, columns and bridges also shall have maximum resistance to heavy rains and floods have caused by them (Syed, 2006). Snowfall and accumulation of it demand relatively high strength structures. The roofs of buildings in mountainous areas and high latitudes should be built so tightly which must have twists to keep heavy snows. Snow density on other horizontal surfaces creates tremendous weight, so in this case construction of complementary and additional safeguards are needed to prevent their flow. It should be noted that the buildings full of ice and snow are vulnerable in cope with other climatic factors such as the wind.

The Wind also has a direct force and pressure on building and structures located on its way. Thus maximum wind speed and pressure must be considered in the design of buildings, towers and bridges. In this regard, calculations based on historical weather records as well as experiments on wind tunnel can help Structural Engineering (climatologically site).

\section{Introduction of the first region of Tehran:}

Area of the first region of municipality is covering an area of approximately 64 square kilometers in height Tehran where the population is about 379,962 people. The area in terms of urban design reflects the rural design and it can be called a garden city. Due to the semi-mountainous and special structure, Shemiranat which is located in South Alborz Mountain is mix of traditional and modern urbanism, although the area has more problems in the field of construction activities but because of oldness and climatic features, it demands additional construction works. Needless to say, the first region of Tehran was required of numerous constructions in the recent past years. The major influx of investments in the construction sector in the region, cause many problems for old Shemiran residents and municipal authorities.

Basic study and comprehensive projects carried out this initiative were in order to avoid duplication and further problems.Developing green space as one of the priorities for the first region. Expansion and preparation of access roads to facilitate travel and also welfare, cultural and sports services in order to meet the basic needs of citizens, especially the younger generation, are the main axes of development planning.

As mentioned the 1st region of Tehran located in the cold and mountainous region. It is recommended to use mud brick in body wall which has high thermal capacity. Using of rubble stone at the foot of brick walls (plinth wall) is an optimal solution to prevent upward (rising) moisture to the walls of the building (Wilson, 1984).

Openings and windows in cold regions: opening dimensions are less extensive in the cold climate in which the exchange heat of interior spaces with the external environment is minimized. By creating wide open openings at the southern side of the building, a significant amount of solar thermal energy could be used in winter.

The area of openings would be minimal in the directions faced with cold winter winds and in some cases they are excluded from facing the cold wind.

The method of controlling the temperature in buildings located in cold climate: to control the temperature in the building we must control heat transfer from inside to outside and vice versa. Common methods for avoiding energy wasting and creating comfort conditions are as follows:

- Using sunlight or deal with it

- Use thermal capacity of building materials to prevent heating and cooling the building

- Wind shelter construction,

- Use the favorable wind currents 


\section{- Minimize heat transfer}

Choose appropriate materials with the climate: areas in which there is only one critical season over a year and thermal conditions of other season is in the comfort zone, building features should be determined on the basis of the critical season. But when there is two critical season (for example too cold winters and very hot summers), heat capacity and resistance of materials shall meet the requirements of both seasons.

Oleg method: in cold regions, to maintain favourable conditions interior of the building, heat resistant of materials should be increased and western walls and the inside of the building should be built with heavy materials. Use of heavy wall for maintaining thermal equilibrium indoor is essential also using thermal insulation on the external surfaces of side walls is required to prevent heat transfer from inside to outside. Since in high latitudes, temperature fluctuations in the cold air and its deviation from the comfort zone are minimal, using materials with thermal resistance is the only way to control indoor temperature.

\section{The introduction of the proposed materials}

a) Nano skins Containing micro wind turbines: these shells surround the building in an organic form and energy requirements of buildings funded by them. Its Concept is organic lattice crust which is composed of micro wind turbines in simple design.

Feynman (1960), American physicist, predicted the device that works at the atomic level. Nano-scale scientif ic discoveries -billionths of meters- go beyond laboratory studies and walk through industrial production and provide effective computer chips and glass coat. Augustine Atcious create elements and equipment in small scale and states in order to achieve the objectives, to create something that is $100 \%$ organic and could use the wind and solar energy.

Natural thin film solar cells to generate electrical energy : even if the uses of synthetic nonmaterial in the shell of buildings and structures is not possible, nanotechnology provide fascinating and extraordinary products for today's architects. Technology for production of natural solar cell slabs with organic ingredients and without the use of industrial materials which is made possible with nanotechnology; this technology challenged traditional Solar system based on silicon material as unlike silicon surfaces, nano products increase barriers such as costs and lack of flexibility and compatibility. Natural and flexible solar cells films can be manufactured on plastic rolls which can significantly reduce the price as compared to conventional technology using glass plates. Plastic solar cells with its flexibility are more compatible with building facades while compared to the rigid and toughened glass sheets which are of heavy weight. For example, some Company now producing Canopies that capture solar energy and convert it into electricity. Research is underway to produce colours in the form of wall cladding layers to absorb solar energy. Soon with the capabilities of nanotechnology throughout the building shell including views and roofs provide the energy requirements of the building as solar energy absorbers.

Solar collector Nano-glass: in nano-glass collector, the whole light spectrum can pass through the glass and thus provide maximum efficiency and the highest energy production for inhibitors. Unlike the old glass, angle the light hits the glass will have a positive impact on its transmission through the glass, in the fact, that these systems are less dependent on the direction and angle of incidence. Therefore they have the same performance in different seasons, time of day and various regions of the world. Furthermore, Nano-coating has the more useful life than traditional ones and are less prone to absorb pollution and dirty.

Stone facades: two groups of natural stones used in building facades are igneous are limestone rocks. Limestones usually do not have much strength due to traces that can be seen in them, and the problem with igneous rocks is low water absorption and lack of adhesion with the building body. Building facades due to exposure to weather conditions (Rain, frost, sun and pollutants) is of utmost importance. Facades must have certain characteristics to be able to cope with these agents. So using the stone in facade must have the following conditions:

i Appropriate to the regional climate: the stone should be chosen to suit the climatic conditions. For example, in cold and wet climate the stone must have a very low porosity because it may collapse due to ice or where there is the light sandstorm, stone subject to wear and should have high abrasion resistance.

ii. Can be polished and cut.

iii. Have a relatively good bending and tensile strengths.

iv. Its mineralogy should be checked: harmful minerals (iron ore) oxidised in contact with air and water, resulting in premature ageing. Impurities integrated into a point or an extension could be the weakness and damage the stone.

v. Selected stone should have good adhesion with mortar (with appropriatewaterabsorption)

vi. The colour should stable in vapour, gases and Sunbeam condition.

v. Selected stone should have good adhesion with mortar (with appropriate waterabsorption).

vi. The color should stable in vapor, gases and Sunbeam condition. 
Table 1 . Rows and stones

\begin{tabular}{lll}
\hline Row & Stone \\
\hline 1 & strength & high thermal capacity/Vernacular \\
2 & weaknesses & restrictions in the design \\
3 & opportunity & ability to hone \\
4 & threatening & itwill be ruined in bad cold condition \\
\hline
\end{tabular}

Concrete: concrete or porous concrete was invented by a Swedish architect in 1924. It was first of all used in Europe under the names of lightweight (Ytong) or (Heblex). This product is prepared by using advanced technology through mixing and baking raw materials: silica sand, lime, cement, aluminum powder and water.

The main properties of concrete (Heblex) is the following:

- Specific weight: $600 \mathrm{~kg}$ percubic meter.

- Compressive strength: 30 to 35 kilogrammes per centimetre square with the possibility of increasing on the specific demand of the consumer demand.

Working with concrete (Heblex) is very easy. For example, it can be made easily saws or put nails in it or could create space for the outlet, power cable and pipes. In addition, concrete is fire-resistant and has all environment health supporting properties.

Heblex = heat, cold, sound and earthquake etc... Insulation .

Heblex $=$ Save iron or fittings, runtime, mortar consumption, wages etc...

Heblex = signif icant adhesion with mortar of cement and plaster to the Department of Housing and Urban Development certified.

Executive benefits: according to the dimensions and lightweight and easily installation of Heblex blocks is 3 times more than other materials.

Economic benefits: building projects using Heblex blocks by considering the speed of implementation needs lower wages. The use of Heblex demands less mortar consumption and reduced loads on structures due to low wall weight. It made the structure smaller and significant savings in the cost of materials would beachieved.

\section{Conclusion:}

To maintain harmony in between the design and climate so that to reduce the energy consumption we must concentrateon:

- Facades of buildings in this region should be in dark color toabsorb more heat energy.

- Use two or more chamber walls with empty space, to prevent heat loss
- Use materials with high thermal capacity, especially new materials that have more efficient modes.combustion never takes place and short combustion time and constant change in fuel ratio, air temperature and chamber conditions of combustion cause variations in the amount of emissions.

Acknowledgements:

We acknowledge all such persons who were directly or indirectly associated with this article.

\section{References:}

Anna-Maria, V. (2009): Evaluation of a sustainable Greek vernacular settlement and its landscape: Architectural typology and building physics. Build. Environ., 44(6):10951106.

El-Rayes, K. \& Moselhi, O. (2001): Impact of rainfall on the productivity of highway construction. J. Cons. Eng. Manag., $127(2), 125-131$.

Fitzharris, B. (2001): Global energy and climate processes. Pub.: Oxford University Press, University of Canterbury. Geography.

Feynman, R.P. (1960): There's Plenty of Room at the Bottom. Eng. Sci., 22-36.

Morel, J.C., Mesbah, A., Oggero, M. \& Walker, P. (2001): Building houses with local materials: means to drastically reduce the environmental impact of construction. Build. Environ., 36(10):1119-1126.

Mahmoodi, M.M. \& Nabavi, S. (2011): The development of climate technology with the approach of sustainable architecture. J.Naghshe Jahan, No 1.

Powers, T.C. (1975): Freezing effects in concrete. American Concrete Institute; $\underline{S p . P u b}$, 47:1-12.

Naeeni , D.S. \& Teimouri ,S. (2016): The recognition of traditional non geometrical drawings (Designs, traces, engravings or paintings) in contemporary buildings. (Case Study: Khayyam and Kamal - ul - Mulk's tombs in NeyshaboorIran). J.Inn. Res. Eng. Sci., 2(2):28-39.

Syed, S. (2006): Atmospheric corrosion of materials. Emirates J. Eng.Res., 11(1):1-24.

Tabriz, S.N., Fard, F.M.T. \& Aliyev, F. (2012): Sustainability patterns in the traditional residential fabric of Tabriz. In N. M'Sirdi et al.(Eds.): Sustainability in Energy and Buildings, SIST 12, pp. 391-402.

Wilson, F. (1984): Masonry (pp. 79-143), In: Building Materials Evaluation Handbook. Springer US.

Xia, F., Liu, X., Xu, J., Yu, L. \& Shi, Z. (2016): Precipitation change between 1960 and 2006 in the Qiantang River basin, eastern China. Clim. Res., 67:257-269. 